\title{
Concentration-discharge and mass flux relationships in two alpine headwater catchments
}

\author{
SARA R WARIX, ELANOR HEIL, ALEXIS NAVARRE- \\ SITCHLER AND KAMINI SINGHA
}

Colorado School of Mines

Presenting Author: swarix@mymail.mines.edu

Stream solute concentrations are a function of both geochemical reactions that produce solutes and the magnitude of discharging streamflow. Concentration-discharge (C-Q) relationships are commonly used to discern hydrochemical processes that control stream chemistry. Temporal analysis of C$\mathrm{Q}$ patterns can reveal changes in hydrogeochemical conditions. However, the interpretations of temporal changes in C-Q as indicators in changes in geochemical conditions may be masked by contemporaneous changes in discharge. In order to parse geochemical from hydrological processes, solute mass flux can be compared to stream discharge. Here, we compared both $\mathrm{C}-\mathrm{Q}$ and mass flux relationships of major weathering products $\mathrm{Ca}^{2+}$ and $\mathrm{SiO}_{2}$ from 1982-2020 for multiple sampling points within two alpine headwater catchments in Colorado to identify both hydrological and geochemical temporal changes. The Andrews Creek Watershed $\left(1.5 \mathrm{~km}^{2}\right)$ and the Albion Creek Watershed (7.1 $\mathrm{km}^{2}$ ) are located along the Continental Divide, are close in elevation (3205 and $3267 \mathrm{~m}$, respectively), and are underlain by granite and gneiss. Both catchments showed a significant increase in $\mathrm{Ca}^{2+}$ through time ( $\mathrm{p}$-value $<0.001$ ) over the last $\sim 40$ years, but only Albion showed an increasing trend in mass flux ( $p$-value $<0.001$ ). The increase in mass-flux indicates changes in geochemical conditions and production of more solutes in Albion, while in Andrews Creek the increases in concentration without an increase in mass flux indicate changes in hydrological conditions alone. The addition of mass flux relationships to C-Q analyses enabled us to parse the effects of seasonality due to changes in discharge. Our results highlight that inclusion of mass flux in C-Q analyses can enable more robust identification of the controls on solute production, which is critical to quantifying how climate change impacts watershed hydrology and weathering processes. 